\title{
Pandemic promenadology: walking for wellbeing in academic life
}

\section{Jana Fedtke}

American University of Sharjah, UAE

Keywords: walking; wellbeing; promenadology; strollology; Covid-19.

\section{The challenge}

Due to the Covid-19 pandemic, traveling and movement in general have been severely restricted. This has meant that people have been confined to their rooms by themselves or in shared spaces. The pandemic has also presented challenges that have had an impact on learning, such as unstructured time, unfamiliarity with digital tools, lack of motivation, emotional distress linked to learning spaces, caring for ill relatives or friends, or general uncertainty for students and educators. Many members of the university community have experienced a sense of fatigue or burnout (Pettit, 2021). Ainsworth and Li (2020) explain the importance of physical activity during a pandemic. In addition, Antunes and Frontini (2021) highlight the connections between physical activity and mental health.

In light of the abrupt shift to emergency online learning, much academic attention has been directed towards remote learning in an effort to cope with these unexpected issues at hand. It is equally necessary to think about one's wellbeing in the face of the sudden onslaught of excessive demands on students, faculty, and staff. As simple as it sounds, walking can be a vital means of improving both mental and physical wellbeing, while also stimulating a person's intellectual abilities. Even though it cannot necessarily fix the issues that the pandemic has caused, walking can provide a renewed focus on wellbeing and can help manage some of the problems. 


\section{The response}

There is a long tradition of scholars who have seen walking as their source of inspiration or wellbeing. Danish philosopher, Søren Kierkegaard, for example, famously advised his niece of the benefits of walking: "Above all, do not lose your desire to walk; every day I walk myself into a state of wellbeing and walk away from every illness; I have walked myself into my best thoughts, and I know of no thought so burdensome that one cannot walk away from it" (cited Percy, 1979). Here are three practical ways to incorporate walking into academic life that have worked for me during the pandemic:

\section{Regular walks as pandemic promenadology}

Walking is a science in and of itself. Professor Martin Schmitz, the only chair of promenadology (German: Spaziergangswissenschaft = walk + science) in Kassel/Germany, knows that "it's all about the concentrated and conscious perception of our environment" (cited Deutsche Welle, 2007). Also known as strollology (Burckhardt et al., 2015), the art of observation and reflection while walking can take various forms, for example, personal walks during a pandemic. For teachers, walking can provide a safe space to think about teaching and learning in peace. During my walks, I have observed nature and my surroundings in more detail, but I have also composed my next lesson plans in my mind and conceptualised future research projects.

\section{Inspiring students to walk}

Instead of constantly sitting at their desks, students can stand up, stretch and walk around in their immediate environment. I have built this into our class time, for example, as a community exercise of as little as three minutes of moving at the very beginning (brainstorming about the topic at hand), in the middle to refresh (reflecting on one specific question related to the subject matter), and once again at the end of a class (simply letting your mind wander and wonder). While it took some practice to get used to this unconventional way of incorporating movement into the classroom, this exercise benefitted both students and the instructor. Neuroscientist Shane O'Mara's (2020) In Praise of Walking emphasises the connection between body and brain: "Walking makes our minds mobile in a fashion denied other animals" (p. 5). He conceives of walking as a holistic 
activity which shows that "walking is hugely beneficial for our minds, our bodies and our communities" (p. 5).

\section{Digital Detox}

Walking can also function as much needed exercise in digital detox, aiming for "balance and awareness more than permanent disconnection" (Syvertsen and Enli, 2019, p. 1269). Away from the omnipresent screen, the mind can relax. During the pandemic, I decided to focus on walks that were independent of technology since they promise digital detox: no phone, no music, no films, no messages and no counting steps. Instead, I focused on my mind, my imagination, the peaceful environment around me and the rhythm of walking. For people who cannot or do not want to walk, it is equally possible to practise this in a wheelchair, riding a bike, or using other means of transportation. The idea is to observe your surroundings, reflect and relax.

\section{Recommendations}

Walking will retain its importance after the pandemic. Some of the following practices can be applied in a post-pandemic world in similar ways:

\section{Walking Classroom}

Originally introduced at the high-school level, the Walking Classroom (2021) can also be tailored to students at the college level (Biber and Heidorn, 2021), as it promotes blended learning and physical activity. Walking can, for example, happen during class discussions and/or outside, especially in smaller classes. In larger classes, walking might have to be incorporated into bite-size exercises of 3-5 minutes, in which the learners can brainstorm the issues at hand individually while walking on their own, most likely in their immediate environment. 


\section{“Twalk" (MELSIG, 2021)}

Another learning space that incorporates walking is the "twalk." According to MELSIG (Media-Enhanced Learning Special Interest Group, 2021):

A \#twalk is a common, structured multi-site learning walk augmented by the use of social media in which all participants act as co-producers of knowledge by addressing ideas and questions together. Usually, a \#twalk combines a one hour learning walk with a tweetchat made up of about 5 landmark-based discussions, with a new discussion prompt being given to redirect the walk and its focus about every ten minutes.

Combining learning, walking, and social media, the twalk is a creative way to co-create content while walking.

\section{Walking meetings}

To increase physical activity and wellbeing, walking meetings present an alternative to traditional meetings for faculty members, staff discussions, and even office hours. Clayton et al. (2015) have shown that walking meetings increase creativity and productivity.

The regularity of walking is a simple technique that most people will be able to implement and keep alive in the post-pandemic future. It does not require any funds or special equipment. Teachers and students can establish their own version of pandemic promenadology: on your own, with peers, or in small groups, in the classroom, in meetings, during your spare time. Deceptively simple, walking has many benefits for one's physical and mental health.

\section{References}

Ainsworth, B. and Li, F. (2020) 'Physical activity during the coronavirus disease-2019 global pandemic', Journal of Sport and Health Science, 9(4), pp.291-292. Available at: https://dx.doi.org/10.1016\%2Fj.jshs.2020.06.004 (Accessed: 25 August 2021). 
Antunes, R. and Frontini, R. (2021) 'Physical activity and mental health in Covid-19 times: an editorial', Sleep Medicine, 77, pp. 295-296. Available at: https://dx.doi.org/10.1016\%2Fi.sleep.2020.10.007 (Accessed 25 August 2021).

Biber, D.D. and Heidorn, J. (2021). 'Tailoring the walking classroom to promote college student engagement', College Teaching 69(3), pp. 169-172. Available at: https://doi.org/10.1080/87567555.2020.1833177 (Accessed: 25 August 2021).

Burckhardt, L. Ritter, M. and Schmitz, M. (2015) Why is landscape beautiful? The science of strollology. Berlin: Birkhäuser. Available at: https://doi.org/10.1515/9783035604139 (Accessed 25 August 2021).

Clayton, R, Thomas, C. and Smothers, J. (2015) 'How to do walking meetings right', Harvard Business Review. Available at: https://hbr.org/2015/08/how-to-do-walkingmeetings-right (Accessed: 25 August 2021).

Deutsche Welle (2007) The science of taking a walk. Available at:

https://www.dw.com/en/the-science-of-taking-a-walk/a-2374179 (Accessed: 25 August 2021).

MELSIG (2021) Twalk Toolkit. Available at:

https://melsig.shu.ac.uk/melsig/resources/twalktoolkit/?doing wp cron=1624468089.1132891178131103515625 (Accessed: 25 August 2021).

O’Mara, S. (2020) In praise of walking - a new scientific exploration. New York: Norton Books.

Percy, W. (1979) The existential Dane. Available at: https://www.nytimes.com/1979/04/01/archives/the-existential-dane-the-dane.html (Accessed: 25 August 2021). 
Pettit, E. (2021) 'Faculty members are suffering burnout. These strategies could help', Chronicle of Higher Education. Available at:

https://www.chronicle.com/article/faculty-members-are-suffering-burnout-so-somecolleges-have-used-these-strategies-to-help (Accessed: 25 August 2021).

Syvertsen, T. and Enli, G. (2019) 'Digital detox: media resistance and the promise of authenticity', Convergence 26 (5-6), pp.1269-1283. Available at: https://doi.org/10.1177\%2F1354856519847325 (Accessed: 25 August 2021).

The Walking Classroom Institute (2021) The Walking Classroom. Available at: https://www.thewalkingclassroom.org/ Accessed: 25 August 2021).

\section{Author details}

Jana Fedtke is Assistant Professor of English at the American University of Sharjah (United Arab Emirates). Her research and teaching interests include transnational literatures with a focus on South Asia; gender studies; and postcolonial literatures. Her work has been published in Online Information Review, Journal of Further and Higher Education, South Asian History and Culture, Asexualities: Feminist and Queer Perspectives (Routledge), and South Asian Review. 